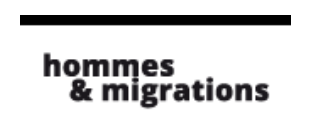

Hommes \& migrations

Revue française de référence sur les dynamiques

migratoires

$1321 \mid 2018$

Les mots de l'exil dans l'Europe du XIXe siècle

\title{
Mustapha Harzoune, Samia Messaoudi, Barbès Café. L'immigration algérienne racontée en chansons
}

Paris, Au Nom de la Mémoire, 2017, 144 p., $15 €$

\section{Belkacem At Salem}

\section{(2) OpenEdition}

12 Journals

Édition électronique

URL : http://journals.openedition.org/hommesmigrations/4562

DOI : ERREUR PDO dans /localdata/www-bin/Core/Core/Db/Db.class.php L.34 : SQLSTATE[HY000]

[2006] MySQL server has gone away

ISSN : 2262-3353

Éditeur

Musée national de l'histoire de l'immigration

Édition imprimée

Date de publication : 1 avril 2018

Pagination : 178-179

ISBN : 978-2-919040-41-4

ISSN : $1142-852 X$

\section{Référence électronique}

Belkacem At Salem, « Mustapha Harzoune, Samia Messaoudi, Barbès Café. L'immigration algérienne racontée en chansons », Hommes \& migrations [En ligne], 1321 | 2018, mis en ligne le 01 avril 2018, consulté le 08 janvier 2021. URL : http://journals.openedition.org/hommesmigrations/4562 ; DOI : https://doi.org/10.4000/hommesmigrations.4562 


\section{LIVRES}

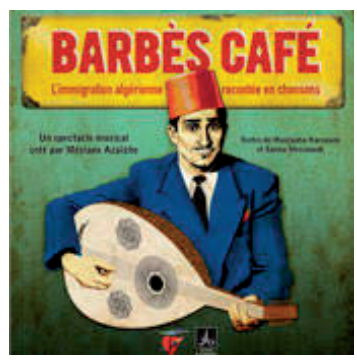

Mustapha Harzoune, Samia Messaoudi

Barbès Café. L'immigration algérienne racontée en chansons

Paris, Au nom de la mémoire, 2017, 144 p., $15 €$

L'histoire de l'immigration algérienne I'histoire franco-algérienne ! - est racontée ici à partir des cafés et autres meublés de l'immigration. À partir d'un spectacle, le Barbès Café, crée par Méziane Azaïche, le directeur du Cabaret sauvage à Paris, et la participation toute scientifique de l'historienne Naïma Yahi. À partir enfin d'une sélection de chansons, de thèmes et de portraits d'artistes, hommes et femmes, particulièrement illustratifs et éloquents. Sans en avoir l'air, ce faisant, cette expérience en arrive à raconter I'histoire autrement, à aborder les trop envahissantes « questions mémorielles » autrement, à tenter de ne pas jeter le bébé avec l'eau du bain, en extirpant de l'oubli la part d'espérance portée par l'exil, et la rencontre. À l'heure des plans de déradicalisation en tout genre et des prêchi-prêcha républicains, une chanson, quelques vers en partage, ne seraient-ils pas plus efficaces? Spinoza, Condorcet, Renan ou Bourdieu même combat disent les auteurs : ne serait-il pas temps de changer de méthode, de "donner envie" comme disait l'autre. Et oui ! l'histoire de l'immigration algérienne pourrait bien renforcer le " désir clairement exprimé de continuer la vie commune " (Renan bien sûr).
Dès les années 1920, les bistros du populo, version algérienne, le café, lqahwa ou kawa des immigrés algériens, se moulent dans cette tradition française qui, depuis le XVIII e siècle, fait de ce lieu un acteur de la vie culturelle et sociale du pays. C'est dans le décor d'un de ces cafés que s'est tenu le spectacle Barbès Café. L'immigration algérienne s'y raconte dans et par l'extraordinaire patrimoine musical laissé en héritage par plusieurs générations d'artistes. Patrimoine insolite, ignoré, méconnu, injustement inemployé - tant sur le plan culturel que pour l'éducation de tous et de chacun. Au Barbès Café, il y a la musique et les dialogues. Ceux de Lucette, la patronne (Annie Papin), et de Mouloud, le client (Salah Gaoua), une Française pure sucre et un kabyle estampillé pure «zit u zemour " (huile d'olive). Tout un symbole.

Le livre, richement illustré par des photos du Barbès Café, restitue la genèse, les préparatifs, les réactions et la philosophie de ce spectacle à la fois musical, théâtral, chorégraphique, historique, patrimonial et même "thérapeutique ». Démarche poétique et politique, les auteurs, à la suite du spectacle, rappellent que les pires échos du passé peuvent encore résonner de nos jours. Oui ! "Voilà voilà que ça recommence " chante Rachid Taha. Et avec cette autre insécurité dont se désintéressent les programmes électoraux.

Pour autant, l'inhospitalité des uns et l'hostilité des lois n'ont pas eu raison de la verticalité de l'immigration, comme elles n'ont pu empêcher la part « belle et rebelle " (Juliette) de l'histoire francoalgérienne. Faut-il aller jusqu'à «imaginer sisyphe heureux" comme l'écrit Camus? Ce serait une façon de restituer 
à chacun sa part de commune humanité. Pour les auteurs, se réapproprier cet esprit de fraternité et de création, c'est se détourner des apprentis sorciers du ressentiment, de la haine de l'autre qui conduisent à la haine de soi et au chaos. Le livre se referme sur quelques enseignements pédagogiques du Barbès café. Une pédagogie qui dessine les contours d'un rapport renouvelé à l'histoire et à la transmission, aide à se mouvoir dans le méli-mélo des « ressources » culturelles et des fidélités, qui rappelle la dignité des générations d'hier et qui, dans le même mouvement, ouvre les plus jeunes à la construction d'un futur qui soit un futur de partage, plutôt que de déchirements. Un peu plus festif aussi.

Belkacem At Salem 